\title{
ANÁlise doS PPC dOS CURSOS DE PEDAgogia OFERTAdOS PELO SISTEMA UAB NA REGIÃO SUL DO BRASIL: INDICATIVOS DE OFERTA E ADESÃO AO SISTEMA UAB
}

\author{
ANALYSIS OF THE PPC OF THE PEDAGOGY COURSES OFFERED BY THE UAB SYSTEM IN \\ THE SOUTH REGION OF BRAZIL: \\ INDICATIVES OF OFFER AND ADHERENCE TO THE UAB SYSTEM \\ ANALISIS DE LOS PPC DE LOS CURSOS DE PEDAGOGIA OFERTADOS POR EL SISTEMA \\ UAB EN LA REGIÓN SUR DE BRASIL: \\ INDICATIVOS DE OFERTA Y ADHESIÓN AL SISTEMA UAB
}

\section{Sandra Letícia Schroeder Iglesias 1 Maria Luísa Furlan Costa ${ }^{2}$}

\begin{abstract}
RESUMO: Este artigo decorre dos resultados obtidos na tese de doutorado em Educação realizada pelo Programa de Pós-Graduação na Universidade Estadual de Maringá. O atendimento as diferentes demandas da sociedade brasileira influenciam o modelo formativo ofertado pelas Instituições de Ensino Superior públicas. Objetivou-se verificar nos Projetos Pedagógicos de Curso dos cursos de Pedagogia, os indicativos que justifiquem sua oferta e adesão ao Sistema Universidade Aberta do Brasil (UAB). A pesquisa é qualitativa, com opção pela análise documental e de conteúdo. Os indicativos encontrados foram: atender as novas exigências do mundo produtivo; democratização do acesso ao Ensino Superior; formação para o uso das tecnologias e acatar os marcos legais, demonstrando a relevância do curso de Pedagogia e do Sistema UAB na perspectiva da educação ao longo da vida. Desmistifica a modalidade a distância como aquela destinada somente aos que não conseguiram estudar no tempo e nas condições regulares de ensino.
\end{abstract}

PALAVRAS-ChAVE: Projeto pedagógico de curso. Pedagogia. Educação a distância. UAB.

ABSTRACT: This article stems from the results obtained in the doctoral thesis in Education carried out by the Graduate Program at the State University of Maringá. Meeting different demands of the society influence the training model offered by Public Higher Education Institutions. The objective was to verify in the Pedagogical Projects of the Courses of Pedagogy, the indicatives that justify their offer and adhesion to the Open University System of Brazil (UAB). The research is qualitative, with the option of documentary and content analysis. The indicatives found were: meeting the new demands of the productive world; democratization of access to higher education; training for the use of technologies and compliance with legal frameworks, demonstrating the relevance of the Pedagogy course and the UAB System in the perspective of lifelong education. It demystifies the distance modality as the one destined only to those who could not study in the time and in the regular conditions of education.

KEYWORDS: Pedagogical course project. Pedagogy. Distance education. UAB.

RESUMEN: Este artículo se deriva de los resultados obtenidos en la tesis de doctorado en Educación realizada por el Programa de Postgrado en la Universidad Estatal de Maringá. La atención a las diferentes demandas de la sociedad influencian el modelo formativo ofrecido por las instituciones de enseñanza superior públicas. Se

\footnotetext{
${ }^{1}$ Submetido em: 08/04/2018 - Aceito em: 21/05/2018 - Publicado em: 02/01/2019
}

\begin{tabular}{l|c|c|c|c|c|c} 
(C) Rev. Educ. Perspec. & Viçosa, $M G$ & v.9 & n.2 & p.363-380 & maio/ago. 2018 & eISSN 2178-8359 \\
\hline
\end{tabular}


objetivó verificar en los Proyectos Pedagógicos de Curso de los cursos de Pedagogía, los indicativos que justifiquen su oferta y adhesión al Sistema Universidad Abierta de Brasil (UAB). La investigación es cualitativa, con opción por el análisis documental y de contenido. Los indicativos encontrados fueron: atención a las nuevas exigencias del mundo productivo; democratización del acceso a la enseñanza superior; formación para el uso de las tecnologías y atención a los marcos legales, demostrando la relevancia del curso de Pedagogía y del Sistema $\mathrm{UAB}$ en la perspectiva de la educación a lo largo de la vida. Desmistifica la modalidad a distancia como aquella destinada solamente a los que no pudieron estudiar en el tiempo y en las condiciones regulares de enseñanza.

PALABRAS CLAVE: Proyecto pedagógico de curso. Pedagogía. Educación a distancia. UAB.

\section{INTRODUÇÃO}

Os cursos de formação inicial de professores brasileiros, principalmente os cursos de Pedagogia ofertados, na modalidade a distância, nas Instituições de Ensino Superior (IES) públicas integradas ao Sistema Universidade Aberta do Brasil (UAB), se expandiram por todo o Brasil e na região sul não foi diferente. As IES públicas, tanto com a oferta do ensino presencial quanto a distância, procuram se organizar de forma a atender demandas da sociedade da informação, do conhecimento e as especificidades de sua abrangência.

Nesta direção, a presente pesquisa objetiva verificar nos Projetos Pedagógicos de Curso (PPC) do curso de Pedagogia, na modalidade a distância, das IES públicas federais e estaduais da região sul do Brasil, os indicativos de oferta do curso de Pedagogia e a adesão ao Sistema UAB, visto que tais razões, em certa medida, influenciam os direcionamentos pedagógicos promovidos pelo curso em virtude do seu atendimento.

Em relação à metodologia, esta pesquisa tem cunho qualitativo, com opção pela pesquisa documental e análise de conteúdo apoiada nos estudos de Bardin (2006), que afirma ser um mecanismo apropriado para trabalhar com materiais textuais escritos, sendo possíveis de serem manipulados pelo pesquisador na procura por respostas, além de permitir compreender suas significações explícitas ou ocultas.

Para tanto, foram selecionadas dez IES que ofertam o curso de Pedagogia na modalidade a distância pelo Sistema UAB na região sul do Brasil e buscou-se os PPC postados na página virtual de cada IES. Deste total, cinco pertencem ao Estado do Paraná: Universidade Estadual de Londrina (UEL), Universidade Estadual de Maringá (UEM), Universidade Estadual do Centro Oeste (Unicentro), Universidade Estadual de Ponta Grossa (UEPG) e Universidade Federal do Paraná (UFPR); duas ao Estado de Santa Catarina: Universidade Federal de Santa Catarina (UFSC) e Universidade Estadual de Santa Catarina (Udesc) e três (3) ao Estado do Rio Grande do Sul: Universidade Federal do Rio Grande do Sul (UFRGS), Universidade Federal do Rio Grande (FURG) e Universidade Federal de Santa Maria (UFSM). 
$\mathrm{Na}$ busca por indicativos da oferta do curso de Pedagogia na modalidade Educação a Distância $(\mathrm{EaD})$, encontrou-se quatro categorias de análise que subsidiaram a discussão: atendimento as novas exigências do mundo produtivo, democratização do acesso ao Ensino Superior, formação dos professores para o uso das tecnologias na educação e acato aos aspectos legais da Lei de Diretrizes e Bases da Educação Nacional (LDBEN) no 9.394/96 (BRASIL, 1996), das Diretrizes Curriculares Nacionais (DCN) do curso de Pedagogia Resolução CNE/CP n ${ }^{o}$ 1/2006 (BRASIL, 2006c) e do Programa Emergencial de Formação de Professores em Exercícios na Educação Básica.

\section{ASPECTOS HISTÓRICOS E LEGAIS DO SISTEMA UAB}

A implementação do Sistema UAB foi realizada a partir do pioneirismo daqueles que acreditaram na modalidade a distância como alternativa educacional pública e em sua possibilidade de democratização. Pessoas que desejavam disponibilizar à população brasileira o acesso e a continuidade de seus estudos, independentemente da situação geográfica em que se encontravam, sua idade ou sua condição social e econômica. Contudo, a UAB foi e continua sendo um processo que necessita romper barreiras conceituais, políticas e econômicas.

O ponto de partida do Sistema UAB no período pós-Lei de Diretrizes e Bases da Educação Nacional $n^{\circ}$ 9.394/96 é a criação, em 2005, do Fórum das Estatais pela Educação cuja finalidade era

[...] propiciar espaço de diálogo e interlocução entre o Ministério da Educação, o Governo Federal, as estatais brasileiras e toda a sociedade brasileira, para análise e debate das questões estratégicas ligadas ao desenvolvimento sustentável do país, com destaque para a busca de soluções dos problemas relacionados à educação (COSTA, 2013, p. 19).

O resultado das discussões realizadas nesse Fórum gerou a proposta da criação de uma Fundação de Fomento à UAB, sem fins lucrativos. Foram necessários dois anos para que os resultados das discussões promovessem a criação do Sistema da Universidade Aberta do Brasil via Decreto $\mathrm{n}^{\circ}$ 5.800/06 (BRASIL, 2006a). Suas finalidades estão dispostas em seu Artigo $1^{\circ}$, parágrafo único:

I - oferecer, prioritariamente, cursos de licenciatura e de formação inicial e continuada de professores da educação básica;

II - oferecer cursos superiores para capacitação de dirigentes, gestores e trabalhadores em educação básica dos Estados, do Distrito Federal e dos Municípios;

III - oferecer cursos superiores nas diferentes áreas do conhecimento;

IV - ampliar o acesso à educação superior pública; 
$\mathrm{V}$ - reduzir as desigualdades de oferta de ensino superior entre as diferentes regiões do País;

VI - estabelecer amplo sistema nacional de educação superior a distância e;

VII - fomentar o desenvolvimento institucional para a modalidade de educação a distância, bem como a pesquisa em metodologias inovadoras (BRASIL, 2006).

Nessa direção, o Sistema UAB vem ao encontro das necessidades educacionais como opção para suprir a demanda reprimida de vagas no Ensino Superior público e dar conta das exigências da LDBEN n 9.394/96 (BRASIL, 1996), principalmente como mecanismo de interiorização, acesso e permanência nesse nível de ensino.

Ao atuar na perspectiva da educação ao longo da vida, o Sistema UAB desmistifica a concepção que a educação a distância é somente destinada aqueles que não conseguiram estudar no tempo e nas condições regulares de ensino. O Sistema UAB vai além do atendimento desse público, pois se direciona para todos os que desejarem reiniciar ou dar continuidade a seus estudos. Dessa forma, se as IES públicas não conseguem suprir a demanda do ensino presencial, o Sistema UAB se encontra como aliado neste processo por meio da modalidade a distância.

Nesse âmbito, a educação brasileira, que se estrutura, em grande medida, a partir dos ditames políticos e econômicos, recebe o Decreto $\mathrm{n}^{\mathrm{o}}$ 5.800/06 (BRASIL, 2006a) como passo importante rumo à consolidação da Educação a Distância nas instituições públicas, visto a criação do Sistema UAB.

No Brasil, o modelo adotado e os inúmeros marcos regulatórios destinados à EaD, após sua legitimação com o Artigo 80 da LDBEN no 9.394/96 (BRASIL, 1996), se inspiraram nas diversas experiências bem-sucedidas realizadas pelas Universidades Abertas (Open University) criadas em diferentes continentes, como na Inglaterra (Open University - OU), em Portugal (Universidade Aberta de Portugal), na Oceania, na Austrália (University of the South Pacific), entre outras. Contudo, tais modelos de EaD, em cada tempo histórico e em cada contexto geográfico, foram e são implementados e praticados de acordo com as tecnologias existentes e a realidade socioeconômica de cada país.

Para Costa (2013), a modalidade a distância ofertada via Sistema UAB permite expandir e interiorizar a oferta de cursos e programas de educação superior. Ressalta-se que o Decreto $\mathrm{n}^{\circ}$ 5.622/05 (BRASIL, 2005), ao ser revogado pelo Decreto $n^{\circ}$ 9.057/17 (BRASIL, 2017), passou a permitir às IES credenciadas criar seus polos de $\mathrm{EaD}$ em respeito à qualidade de infraestrutura exigida pelo MEC e disponibilizar a modalidade sem oferta simultânea do ensino presencial. O Decreto estabelece e expande essa alteração também para a oferta de cursos de pós-graduação lato sensu. Dentre as ações que envolvem os cursos na modalidade a 
distância, encontra-se o PPC que, além de expressar as concepções filosóficas, axiológicas e ontológica da IES, denotam a organicidade dos cursos.

\section{Projeto Pedagógico de Curso do curso de pedagogia}

O PPC, como um documento legal, normativo, programático e norteador das ações a serem desenvolvidas num curso de formação é obrigatório e deve conter os fundamentos, as concepções, orientações curriculares e organizacionais de uma instituição ou curso. Dessa maneira, as concepções refletem o pensamento dos que atuam nas IES e devem efetivar o que nele foi projetado. Isso implica diversos fatores, entre eles: a associação entre a teoria e a prática, o ensino e a pesquisa e a fundamentação teórica e prática como suporte indispensável nas compreensões e reflexões sobre a prática pedagógica na futura atuação do profissional pedagogo.

Um PPC de graduação deve considerar, a priori, as diretrizes do Projeto Pedagógico Institucional (PPI) e o Plano de Desenvolvimento Institucional (PDI). Este último, por sua vez, deve contemplar as especificidades de cada curso, da comunidade escolar e das regiões que atende, com o objetivo de imprimir um caráter de totalidade e com clara articulação entre os documentos. Mais do que isso, o PPC deve orientar o planejamento das disciplinas na busca por concretizar a política educacional da IES.

Quando desconsiderada a relevância do PPC, há uma visão reducionista e meramente cumpridora dos trâmites legais exigidos que em muito pouco podem alterar a situação vigente dos cursos. Perde-se, portanto, a oportunidade de atualizá-los frente às necessidades que a sociedade apresenta como nova forma de perceber e organizar o trabalho pedagógico a ser desenvolvido na IES.

As Diretrizes Curriculares Nacionais de 2006 para o Curso de Pedagogia são consideradas como relevante marco regulatório que direciona a organização dos PPC. As DCN/06 sugerem uma formação flexível e que valorize diferentes concepções teórico-metodológicas, o que deixa uma abertura para um perfil de formação do pedagogo conforme os princípios de cada IES. Isso, de certa forma, provoca críticas ao documento, mas, por outro lado, imprime autonomia às IES, visto que cada uma visa atender suas especificidades e demandas. Entre tais necessidades se encontram exigências do mundo do trabalho, como formação para o uso das tecnologias, atendimento aos aspectos legais do curso, respeito às características culturais, econômicas e regionais, entre outras. 


\section{Indicativos de adesão ao Sistema UAB pelas IES}

O atendimento ao objetivo desta pesquisa contou com o acesso às páginas virtuais oficiais das referidas instituições em busca da postagem do PPC e dos indicativos de adesão ao Sistema UAB. Isso ocorreu após leitura, na íntegra, dos documentos postados nos anos 2016 e 2017. As justificativas apresentadas para adesão ao sistema, juntamente com a oferta do curso de Pedagogia na modalidade a distância, se encontram delineadas de acordo com a relação das instituições elencadas.

No Estado do Paraná, a UEL passa a ofertar, no âmbito do Sistema Universidade Aberta do Brasil, o Curso de Primeira Licenciatura em Pedagogia na modalidade a distância em virtude, principalmente, do Programa Emergencial de Formação de Professores em Exercício na Educação Básica.

As justificativas apresentadas pela UEL levam em consideração: os aspectos legais contidos no Decreto $\mathrm{n}^{\circ}$ 5.622/05 (BRASIL, 2005) que regulamentam o Artigo 80 da LDBEN $\mathrm{n}^{\circ}$ 9.934/96, o Decreto $n^{\circ}$ 5.733/06 (BRASIL, 2006b), que dispõe sobre o exercício das funções de regulação, supervisão e avaliação das IES e cursos superiores de graduação e sequenciais do sistema federal de ensino, o Decreto $\mathrm{n}^{\circ}$ 6.303/07 (BRASIL, 2007), que altera os dispositivos do Decreto $n^{\circ}$ 5.622/05 (BRASIL, 2005), o Decreto $n^{\circ}$ 6.755/09 ((BRASIL, 2009), que institui a Política Nacional de Formação de Profissionais do Magistério da Educação Básica, a Resolução CNE/CP n 0 01/02 (BRASIL, 2002a), que institui as Diretrizes Curriculares Nacionais para a Formação de Professores da Educação Básica em nível superior, curso de licenciatura, de graduação plena, a Resolução CNE/CP nº 02/02 (BRASIL, 2002b), que institui a carga horária dos cursos de licenciatura de graduação plena, a Resolução CNE/CP n 01/06 (BRASIL, 2006), que institui as DCN para o Curso de Pedagogia, o Programa Emergencial de Formação de Professores em exercício na Educação Básica Pública, a Resolução CEPE nº 0051/10 (UEL, 2010), que regulamenta a criação dos cursos na modalidade a distância na UEL, a Deliberação da Câmara de Graduação no 001/11 (UEL, 2011), que estabelece adequações curriculares à Resolução CEPE/CA n 0245/09 (UEL, 2009) e o Parecer CNE/CES nº 136/10 (BRASIL, 2010), que trata da Regularidade da Autorização conferida à Faculdade Vizinhança Vale do Iguaçu (Vizivali), instituição do sistema estadual para oferta do Programa Especial de Capacitação em Serviço destinado a docentes na Educação Infantil e Anos Iniciais do Ensino Fundamental.

Nesse sentido, apesar de não apresentar, em seu texto, referências literais para uma formação em que as tecnologias sejam consideradas como aspecto integrante, a UEL se utiliza dos marcos legais e suas exigências que, no desencadear, fazem determinadas menções às tecnologias que acabam por exigir a sua inserção na composição do seu PPC. Esse 
atendimento às exigências postas nos marcos legais, apesar de não estarem claras e literalmente expostas em seu texto, levam a crer que os cursos de Pedagogia deverão apresentar, em seu PPC, direcionamentos teóricos e técnicos quanto ao uso das tecnologias no referido curso.

A UEM, em seu Projeto Pedagógico do curso de Pedagogia, na modalidade a distância, evidencia a necessidade da "formação de professores para as séries iniciais do Ensino Fundamental e da Educação Infantil como uma prioridade nacional” (COSTA, 2013, p. 1) e ampliação da oferta de vagas para o acesso ao Ensino Superior, em especial os cursos de Licenciatura.

Inicialmente, na UEM, essa oferta de formação era destinada aos "professores em exercício do magistério dos Anos Iniciais do Ensino Fundamental da região Noroeste do Estado do Paraná, que necessitam receber qualificação, em nível superior, para dar cumprimento ao Art. 87 da LDBEN n ${ }^{\circ}$ 9.394/96 até o ano de 2007" (COSTA, 2013, p. 1). Para esse atendimento, a UEM criou, no final do ano 2000, o seu primeiro curso de graduação na modalidade a distância em parceria com a Universidade Federal do Mato Grosso (UFMT) (UEM, s.d.).

Em 2004, foi constituída uma comissão de professores com experiência em curso na modalidade a distância, da UEM, para a elaboração de um novo projeto pedagógico direcionado ao Curso Normal Superior: Licenciatura dos Anos Iniciais do Ensino Fundamental, o qual recebeu essa denominação por recomendação do MEC e da Comissão de Avaliação desse ministério. Nesse período, o projeto pedagógico, além de assegurar as Diretrizes Curriculares Nacionais para a formação de professores, atendeu também aos Referenciais de Qualidade da Secretaria de Educação a Distância do MEC. Paralelo a esse processo, dava-se o credenciamento da UEM para cursos na modalidade a distância.

Além dos aspectos legais que envolvem as justificativas para a oferta do curso de Pedagogia, na modalidade a distância, na UEM, vinculado ao Sistema UAB, encontram-se aqueles que se referem à necessidade de atendimento às demandas do mundo contemporâneo decorrente da economia, desenvolvimento científico e tecnológico permeados pela globalização. Para a UEM, na sociedade do conhecimento, é acentuado o acesso à educação como mecanismo indispensável na "construção da cidadania, da justiça, da tolerância; para o combate à desigualdade, à exclusão, ao preconceito e, principalmente, para a preparação para o trabalho" (COSTA, 2013, p. 2), tanto para os que "não tiveram a oportunidade de frequentála em seu devido tempo como dos altamente instruídos" (COSTA, 2013, p. 2).

A UNICENTRO iniciou suas primeiras ações institucionais em relação à educação a distância, em 2003, com pouca adesão de professores. Em 2005, inseriu-se no Programa Prólicenciatura do MEC por meio do consórcio EAD/Centro Sul, em parceria com a UEM e a

\begin{tabular}{l|c|c|c|c|c|c} 
(C) Rev. Educ. Perspec. & Viçosa, $M G$ & v.9 & n.2 & p.363-380 & maio/ago. 2018 & eISSN 2178-8359 \\
\hline
\end{tabular}


Faculdade de Filosofia, Ciências e Letras de Paranavaí. A justificativa da oferta da modalidade a distância se dá ao se considerar

[...] como um Polo de disseminação de conhecimento para pessoas que residem em vários municípios do Estado do Paraná e, muitas vezes, em locais que não possuem universidades ou faculdades. Além disso, a educação a distância procura atender com eficácia a autonomia do sujeito na construção de saberes científicos, bem como na formação para atuação reflexiva na sociedade (COSTA, 2013, p. 32).

Outra justificativa da UNICENTRO se reporta à necessidade de ações que contribuam para a superação dos Índices de Desenvolvimento Humano (IDH) da região. Esse índice é considerado baixo e destoa da média apresentada no Estado do Paraná. De acordo com seu PPC, a IES objetiva colaborar no processo de difusão do conhecimento científico para os diferentes segmentos sociais, oportunizar o acesso ao saber acadêmico com vistas à redução das desigualdades sociais, possibilitar a qualificação profissional e favorecer a melhoria da qualidade de vida da região que atende (UNICENTRO, 2015).

Foi em 2008 que a UNICENTRO passou, de forma definitiva, a ofertar cursos na modalidade a distância e integrou-se ao Sistema Universidade Aberta do Brasil. Intensificou suas ações, sua demanda aumentou e ampliou suas atividades na produção de material didático, formação docente e maior oferta de vagas nos cursos de graduação, pós-graduação e de aperfeiçoamento.

A UFPR (s.d.), apesar de disponibilizar em sua página oficial virtual informações sobre a oferta do curso de Pedagogia, na modalidade a distância, não há postagem do Projeto Pedagógico de Curso da Pedagogia.

A UEPG iniciou a oferta do curso de Pedagogia - Magistério da Educação Básica e Gestão Educacional - na modalidade a distância, em 2009, aderindo ao Sistema UAB. Em seu PPC, alega que seus princípios se encontram preconizados pela legislação nacional, com base nas Diretrizes Curriculares Nacionais para o curso de Pedagogia/2006. A UEPG reconhece a educação como prática social e, como tal, "traduz-se a partir de finalidades sociopolíticas, ao propor uma ação educativa diretamente voltada a um projeto de gestão social e política da sociedade" (UEPG, 2009, p. 2). Ela atende alguns municípios do Estado do Paraná e de Santa Catarina e seu PPC está voltado para a formação para a docência e gestão educacional. Essa formação deve conferir especificidade à função do profissional da educação, entendida como ato educativo intencional no trabalho pedagógico escolar ou não-escolar, bem como compreender a gestão como base para a organização do trabalho pedagógico, oferecer uma formação inicial para pesquisa, entendida como um processo imprescindível ao profissional da educação e promover a formação do pedagogo como intelectual crítico consciente do compromisso social, ético e político. 
No Estado de Santa Catarina, a UFSC (s.d.), apesar de ofertar outros cursos na modalidade a distância e no âmbito do Sistema UAB, não disponibilizou, no período dessa pesquisa, a oferta de vagas para o curso de Pedagogia, nessa modalidade. Seu PPC, sua estrutura curricular e as ementas do curso também não se encontram disponibilizados em sua página virtual.

No mesmo Estado, a Udesc ressalta que seu Projeto Pedagógico de Curso, na modalidade a distância, surgiu no Centro de Ciências da Educação (Faed-Udesc). Seu histórico revela que foi originado das ações desenvolvidas, desde 1991, em 14 municípios da Região da Grande Florianópolis pelo Núcleo de Apoio Pedagógico (Nape), direcionadas à capacitação docente e à consultoria e assessoria na definição de encaminhamentos didático-pedagógicos para as políticas educacionais desses municípios. O PPC da Udesc (2009) assinala que a implantação do curso de Pedagogia foi gerada a partir das

[...] inúmeras solicitações de educadores na busca de uma melhor qualificação, especialmente aqueles que se viam impossibilitados de frequentar um curso superior presencial em razão da distância e da falta de disponibilidade de tempo para se deslocarem e participarem das aulas diariamente, que aflorou a ideia de se buscar uma alternativa para responder a essa demanda de formação docente (UDESC, 2009, p. 1).

Diante dessas solicitações, um grupo de professores do Centro de Ciências da Educação iniciou estudos com o objetivo da criação e implantação do Núcleo de Educação a Distância (Nead). Em 03 de abril de 1999, a Udesc recebeu a Comissão Verificadora, designada pela Secretaria de Ensino Superior (SESU-MEC), para a avaliação do pleito e recebeu parecer "favorável ao credenciamento da Universidade do Estado de Santa Catarina para oferecer o curso de Pedagogia na modalidade à distância” (UDESC, 2009, p. 2).

O Projeto do Curso de Pedagogia, na modalidade a distância, da Udesc, foi denominado Projeto Piloto. Ele atendeu 14 municípios da região da Grande Florianópolis, com os quais a instituição mantinha vínculo de cooperação. Por se caracterizar como um projeto inicial, optou-se por restringir a zona de abrangência e o número de professores envolvidos. A qualidade do curso e a necessidade de atendimento às exigências da LDBEN nº 9.394/96 (BRASIL, 1996) quanto à formação de professores para a educação básica, aliadas à conciliação entre tempo para o estudo e a ausência de deslocamento para tal, despertaram o interesse de grande número de alunos. Decorrente disso,

[...] foram inúmeras as solicitações de vagas ao recém-criado curso de Pedagogia a Distância, oriundas das Prefeituras Municipais, de instituições particulares e da Secretaria Estadual de Educação, que desejavam oportunizar aos seus docentes o acesso ao ensino superior (UDESC, 2009, p. 2). 
Ante esta experiência de sucesso, na modalidade a distância, e o alargamento do horizonte geográfico e ampliação do número de vagas, o curso de Pedagogia, da Udesc, se reestruturou e passou seu alcance a 60 municípios. Em uma terceira etapa, passou a 100 municípios e, aproximadamente, 13 mil alunos: "o dobro do número de estudantes matriculados nos cursos presenciais da Udesc” (UDESC, 2009, p. 3). Esse número contou, também, com alunos ligados a movimentos sociais de ação afirmativa como afro-brasileiros, alunos cegos e surdos. Isto levou o curso a recorrer a metodologias apropriadas, profissionais habilitados na Língua Brasileira de Sinais (Libras) e transcrições de seu material auto-instrucional para o Sistema Braille.

No Estado do Rio Grande do Sul, a UFRGS passou a ofertar cursos, na modalidade a distância, no âmbito do Sistema UAB, a partir de 2006. Todavia, o documento que se encontra postado em sua página virtual não apresenta data. Justifica-se a sua implantação pela necessidade de se considerar a dimensão histórica, política e sociocultural, na qual se encontra inserida. Entende que "o ensino é práxis social, resultante das interações que mediam a construção do conhecimento no sentido de permitir aos sujeitos envolvidos neste processo refletirem sobre a própria cultura e os contextos sociais a que pertence" (UFRGS, s.d., p. 2). Todavia, há necessidade da oferta de uma formação de pedagogos com "programas consistentes, atualizados e inovadores, quer se trate de sua formação inicial regular quer da formação em serviço" (UFRGS, s.d., p. 3). A instituição também considera como justificativas:

\begin{abstract}
a) a reestruturação do mundo do trabalho decorrente do constante avanço tecnológico e o consequente aumento das exigências de qualificação profissional demarcada especialmente pela capacidade de rápidas adaptações às inovações;

b) o crescimento igualmente acelerado dos conhecimentos científicos postos à disposição da sociedade e as rápidas mudanças culturais que ocorrem nas artes, na comunicação e nos valores sociais;

c) o caráter aparentemente inevitável da globalização econômica que visa a expansão do sistema produtivista, cujos efeitos mais visíveis do ponto de vista social são o temor em relação ao crescente esgotamento dos recursos naturais em função dos modelos de produção e de consumo contemporâneos, que agrava os problemas de desemprego, exclusão social, com o consequente aumento das desigualdades sociais (UFRGS, s.d., p. 3).
\end{abstract}

A UFRGS reconhece e explicita, em seu PPC, uma formação voltada às mudanças no mundo produtivo e a urgência de uma formação voltada para as questões que envolvem o uso das tecnologias. Também alerta para possíveis exclusões que a falta do seu domínio teórico e prático possa acarretar, tanto na vida profissional quanto social.

No mesmo Estado, a FURG (2010, p. 5) direciona “[...] suas ações, procedimentos e propósitos por meio de atividades de ensino, pesquisa e extensão, a partir e para as urgências das demandas locais". Pertencente a uma região costeira, tende à compreensão das interrelações entre os organismos ao incluir o ser humano e o meio ambiente. Como justificativa

\begin{tabular}{l|l|l|l|l|l|l} 
(c) Rev. Educ. Perspec. & Viçosa, $M G$ & v.9 & n.2 & p.363-380 & maio/ago. 2018 & eISSN 2178-8359 \\
\hline
\end{tabular}


para a implantação do curso de Pedagogia a distância, no âmbito do Sistema UAB, a FURG cita a democratização do acesso ao Ensino de Graduação, principalmente, "por questões legais, pelas perspectivas de formação docente para este milênio e pelas necessidades apontadas pelo próprio Ministério da Educação" (FURG, 2010, p. 6).

Ressalta-se a preocupação com questões voltadas às tecnologias, visto que a primeira iniciativa da FURG foi com a implementação do Programa "Mídias na Educação", de 2003 a 2006, resultante da parceria entre a Secretaria de Educação a Distância/MEC, universidades públicas e secretarias de educação para a formação continuada de professores da Educação Básica. No âmbito do Sistema UAB, seu funcionamento se deu a partir de 2007.

A FURG está voltada para as demandas dos municípios que integram o Cordão Litorâneo Sul-rio-grandense: Chuí, Santa Vitória do Palmar, Rio Grande, São José do Norte, São Lourenço do Sul, Tavares, Mostardas, Capivari do Sul, Palmares do Sul e Santo Antônio da Patrulha. Essa região necessita de um redirecionamento do modelo econômico e das políticas de desenvolvimento, inclusive educacional, visto a "reconversão da economia do litoral sul do estado, na busca de um sistema produtivo de maior padrão tecnológico, competitivo, que possibilite a melhoria da qualidade de vida da população" (FURG, 2010, p. 9). Como consequência do desenvolvimento e da transferência de tecnologias para empresas, exige-se formação de mão de obra especializada como fator fundamental para o desenvolvimento sustentável da região, redução das desigualdades sociais e do nível de desemprego.

Outra justificativa apresentada no PPC é a necessidade de "formar profissionais para o uso das novas tecnologias da informação" (FURG, 2010, p. 10) com vistas à adoção de novas práticas de ensino-aprendizagem. O PCC evidencia e preconiza que a utilização das novas tecnologias de ensino contribuirá para o desenvolvimento da educação a distância e na área educacional. Essa proposta demonstra a necessidade de o curso de Pedagogia se direcionar para um currículo em que os conhecimentos necessários sobre tecnologias sejam essenciais para suprir exigências atuais da sociedade e da demanda local.

Já a UFSM organizou seu PPC do Curso de Pedagogia, na modalidade a distância, bem como sua matriz curricular, a partir da legislação e dos resultados das discussões previamente realizadas pelos professores e alunos do curso de Pedagogia presencial. No entanto, no documento encontrado na página virtual, não há data. Os resultados das discussões alertavam para a necessidade de uma formação que superasse

[...] a vigência de um currículo calcado mais no acúmulo de conhecimentos que geravam a superposição dos mesmos, não conseguindo, em alguns casos, gerar a reflexividade crítica exigida para um profissional comprometido com o avanço científico na sua área de atuação. Os aportes teóricos que balizaram os estudos no interior deste curso eram incoerentes, levando os acadêmicos a vivenciarem uma 
maneira de ensinar e de aprender distantes da realidade e das necessidades dos espaços escolares (UFSM, s.d., p. 1).

Os pressupostos apontados serviram de base para a instituição de um novo currículo para o curso de Pedagogia da UFSM, “[...] que refletisse e integrasse as necessidades do contexto histórico no qual estava inserido, corroborando com possibilidades futuras para a formação do professor, em consonância com o projeto de uma sociedade mais justa, democrática e participativa" (UFSM, s.d., p. 2).

O texto do PPC da UFSM chama a atenção para uma formação do professor que contemple em seu projeto curricular uma visão profissional ampla e integrada entre os aspectos da formação e da ação profissional. O PPC da UFSM assumiu o compromisso de formar o pedagogo para atuar na Educação Infantil e nos Anos Iniciais do Ensino Fundamental, inclusive na modalidade de Educação de Jovens e Adultos (EJA).

Ao verificar as justificativas que levaram à oferta do curso de Pedagogia, na modalidade a distância, no âmbito do Sistema UAB, pelas universidades pesquisadas, constata-se que estas se pautam em diversos motivos. Para melhor síntese dessas justificativas, optou-se por reunilas pela sua proximidade em quatro categorias demonstradas no Quadro 1.

Quadro 1. Justificativas apresentadas pelas IES para a oferta do curso de Pedagogia, na modalidade a distância, no âmbito do Sistema UAB, na região sul do Brasil

\begin{tabular}{|c|l|}
\hline IES & \multicolumn{1}{c|}{ JUSTICATIVAS } \\
\hline $\begin{array}{c}\text { UEM; UFRGS; FURG } \\
\text { UFRGicentro; UEPG; Udesc; }\end{array}$ & Atendimento às novas exigências do mundo produtivo. \\
\hline FURG & Democratização do acesso ao Ensino Superior. \\
\hline UEL; UEM; UEPG; FURG; UFSM & $\begin{array}{l}\text { Acatar os aspectos legais da LDBEN no 9.394/96, das DCN do curso de } \\
\text { Pedagogia/06 e o Programa Emergencial de Formação de Professores em } \\
\text { Exercícios na Educação Básica. }\end{array}$ \\
\hline
\end{tabular}

Fonte: Quadro elaborado pelas pesquisadoras (2016), a partir de dados coletados nos PPC dos cursos de Pedagogia das IES.

A primeira categoria se refere às novas exigências do mundo produtivo. As instituições UEM, UFRGS e FURG abordam, em seus documentos, a necessidade do atendimento à demanda do mundo produtivo que se tornou mais competitivo devido aos avanços tecnológicos, que passaram a exigir profissionais com habilidades no trato das tecnologias e alta capacidade de adaptação às mudanças por elas provocadas. A formação de profissionais com habilidades no trato das tecnologias amenizaria o processo de exclusão social causado pela falta do conhecimento sobre elas e atenuaria, em certa medida, os níveis de desigualdade social. 
A segunda categoria versa sobre a democratização do acesso ao Ensino Superior. As instituições UEM, UNICENTRO, UEPG, Udesc, UFRGS e UFSM expõem em seus textos a necessidade de ampliar o atendimento à demanda de alunos que residem em locais distantes, que não possuem IES. Outro fator diz respeito aos alunos que não possuem condições de frequentar um ensino presencial devido ao trabalho, tempo ou outros motivos. $\mathrm{O}$ acesso ao Ensino Superior é caracterizado como uma práxis social, na qual a promoção da aquisição do conhecimento favorece o sujeito a refletir e interagir sobre sua realidade profissional, pessoal e/ou social. Os fatores elencados pelas IES se direcionam para o atendimento de alguns dos objetivos propostos pelo Sistema UAB, cujo eixo norteador é o rompimento das distâncias geográficas e temporais ao tornar o Ensino Superior acessível a todos. Trata-se de um desafio educacional voltado para a necessidade de uma formação inicial que agregue criticidade à uma atividade já existente e que, para tanto, haja uma base teórica e epistemológica consistente que permita ao egresso realizar "movimento permanente entre o particular e o universal, entre a estrutura e a conjuntura, entre a parte e o todo como elementos de uma totalidade histórica" (GRAMSCI, 1981, p. 18). Dessa forma, poderia romper com visões fragmentadas de mercado e de ideologias em um caráter ativista voltado para o bem comum.

A terceira categoria menciona a formação para o uso das tecnologias na educação. A FURG cita a necessidade formativa de profissionais da educação que dominem as tecnologias da informação voltadas para as questões educativas. Isto é, que o seu uso seja direcionado para a adoção de novas práticas metodológicas que possam contribuir para a melhoria da qualidade do processo de ensino e aprendizagem.

A quarta categoria se reporta ao atendimento dos aspectos legais. As instituições UEL, UEM, UEPG, FURG e UFSM assinalam o cumprimento das prerrogativas dispostas na LDBEN $n^{\circ}$ 9.394/96 (BRASIL, 1996) e seu Artigo 87 que preconizam a Década da Educação e a necessidade de atender a um grande contingente de pessoas. As justificativas dessas instituições se concentram também no atendimento às DCN do Curso de Pedagogia/06 e ao Programa Emergencial de Formação de Professores em Exercício na Educação Básica.

\section{CONSIDERAÇÕES FINAIS}

No transcorrer das últimas décadas, a formação de profissionais do magistério da educação básica, nas modalidades presencial e a distância, se tornou um campo de disputa de concepções, dinâmicas, políticas e currículos que buscam a organicidade, a qualidade e o atendimento às demandas da sociedade.

As diversas justificativas apresentadas nos PPC que envolvem a oferta do curso de Pedagogia e a adesão ao Sistema UAB revelam tanto a importância quanto a relevância de ambos para o

\begin{tabular}{l|l|l|l|l|l|l|} 
(C) Rev. Educ. Perspec. & Viçosa, $M G$ & v.9 & n.2 & p.363-380 & maio/ago. 2018 & eISSN 2178-8359 \\
\hline
\end{tabular}


sistema educacional brasileiro, principalmente pelo fato do Sistema UAB atuar na perspectiva da educação ao longo da vida, visto que desmistifica a concepção que a educação a distância é somente destinada aqueles que não conseguiram estudar no tempo e nas condições regulares de ensino. O Sistema UAB vai além do atendimento desse público. Ele é direcionado a todos os que desejarem reiniciar ou dar continuidade a seus estudos. Dessa forma, se as IES públicas não conseguem suprir a demanda do ensino presencial, o Sistema UAB se encontra como aliado nesse atendimento por meio da modalidade a distância.

Portanto, a reorganização e atualização dos PPC se faz necessária para que estejam em consonância com os marcos legais e promovam formação inicial consistente nos aspectos epistemológicos e práticos. Dessa forma, se faz necessário novas pesquisas que contribuam com a temática apresentada e, assim, somar para com o Ensino Superior ao atender as funções da modalidade a distância e presencial que, entre tantas, busca acolher as demandas da sociedade que se alteram em cada tempo histórico.

\section{REFERÊNCIAS}

BARDIN, Laurence. Análise de conteúdo. Tradução de Luís Antero Reto e Augusto Pinheiro. Lisboa: Edições 70, 2006.

BRASIL. Decreto $\mathbf{n}^{\circ}$ 5.622, de 19 de dezembro de 2005. Revogado pelo Decreto $\mathrm{n}^{\circ}$ 9.057, de 2017. Brasília, DF: 2005. Disponível em: http://www.planalto.gov.br/ccivil_03/_ato20042006/2005/decreto/d5622.htm. Acesso em: 5 jan. 2018.

BRASIL. Decreto no 5.800, de 8 de junho de 2006. Dispõe sobre o Sistema Universidade Aberta do Brasil - UAB. Brasília, DF: 2006a. Disponível em: http://www.planalto.gov.br/ccivil_03/_ato2004-2006/2006/decreto/d5800.htm. Acesso em: 6 jan. 2018.

BRASIL. Decreto $n^{0}$ 5.733, de 9 de maio de 2006. Dispõe sobre o exercício das funções de regulação, supervisão e avaliação de instituições de educação superior e cursos superiores de graduação e sequenciais no sistema federal de ensino. Brasília, DF: 2006b. Disponível em: http://portal.mec.gov.br/seed/arquivos/pdf/legislacao/decreton57731.pdf. Acesso em: 08 jan. 2016.

BRASIL. Decreto $n^{0}$ 6.303, de 12 de dezembro de 2007. Revogado pelo Decreto ${ }^{\circ} 9.235$, de 2017. Brasília DF: 2007. Disponível em: http://www.planalto.gov.br/ccivil_03/_ato20072010/2007/decreto/d6303.htm. Acesso em: 09 dez. 2016.

BRASIL. Decreto $\mathbf{n}^{\circ}$ 6.755, de 29 de janeiro de 2009. Revogado pelo Decreto $\mathrm{n}^{\circ} 8.752$, de 2016. Brasília DF: 2009. Disponível em: http://www.planalto.gov.br/ccivil_03/_ato20072010/2009/decreto/d6755.htm. Acesso em: 12 dez. 2016.

\begin{tabular}{l|c|c|c|c|c|c} 
(C) Rev. Educ. Perspec. & Viçosa, $M G$ & v.9 & n.2 & p.363-380 & maio/ago. 2018 & eISSN 2178-8359 \\
\hline
\end{tabular}


BRASIL. Decreto no 9.057/2017. Brasília, DF: 2017. Disponível em: http://www.planalto.gov.br/ccivil_03/_ato2015-2018/2017/decreto/D9057.htm. Acesso em: 08 dez. 2017.

BRASIL. Lei de Diretrizes e Base da Educação Nacional n 9.394/96. Estabelece as diretrizes e bases da educação nacional. Brasília, DF: 1996. Disponível em: http://www.planalto.gov.br/ccivil_03/leis/L9394.htm. Acesso em: 6 jan. 2018.

BRASIL. Parecer CNE/CES no 136, de 8 de julho de 2010. Regularidade da autorização conferida à Faculdade Vizinhança Vale do Iguaçu (VIZIVALI), instituição do sistema estadual, para a oferta do Programa Especial de Capacitação em Serviço destinado aos docentes da Educação Infantil e Séries Iniciais do Ensino Fundamental. Brasília, DF: 2010. Disponível em: http://portal.mec.gov.br/index.php?option=com_docman\&view= download\&alias=6288-pces136-10\&category_slug=agosto-2010-pdf\&Itemid=30192. Acesso em: 16 mar. 2018.

BRASIL. Resolução CNE/CP n ${ }^{0}$ 1, de 18 de Fevereiro de 2002. Institui Diretrizes Curriculares Nacionais para a Formação de Professores da Educação Básica, em nível superior, curso de licenciatura, de graduação plena. Brasília, DF: 2002a. Disponível em: http://portal.mec.gov.br/seesp/arquivos/pdf/res1_2.pdf. Acesso em: 5 jan. 2018.

BRASIL. Resolução CNE/CP n 2, de 19 fevereiro de 2002. Institui a duração e a carga horária dos cursos de licenciatura, de graduação plena, de formação de professores da Educação Básica em nível superior. Brasília, DF: 2002b. Disponível em: http://portal.mec.gov.br/cne/arquivos/pdf/CP022002.pdf. Acesso em: 16 mar. 2018.

BRASIL. Resolução CNE/CP no 1, de 15 de maio de 2006. Institui Diretrizes Curriculares Nacionais para o Curso de Graduação em Pedagogia, licenciatura. Brasília, DF: 2006c. Disponível em: http://portal.mec.gov.br/cne/arquivos/pdf/rcp01_06.pdf. Acesso em: 5 jan. 2018.

COSTA, Maria Luísa Furlan. Educação a distância no Brasil. Maringá: Eduem, 2013. $130 \mathrm{p}$.

FURG. Universidade Federal do Rio Grande. Secretaria de Educação a Distância (SEaD). 2010. Disponível em: http://www.sead.furg.br/. Acesso em: 5 jan. 2018.

GRAMSCI, Antonio. Concepção Dialética de História. Rio de Janeiro: Civilização Brasileira, 4 ed., 1981. 341p.

UDESC. Universidade do Estado de Santa Catarina. 2009. Disponível em: http://www.udesc.br/. Acesso em: 5 jan. 2018.

UEL. Universidade Estadual de Londrina. Deliberação da Câmara de Graduação no 001, de 15 de fevereiro de 2011. Estabelece adequações curriculares à Resolução CEPE/CA n ${ }^{\circ}$

\begin{tabular}{l|c|c|c|c|c|c} 
(C) Rev. Educ. Perspec. & Viçosa, $M G$ & v.9 & n.2 & p.363-380 & maio/ago. 2018 & eISSN 2178-8359 \\
\hline
\end{tabular}




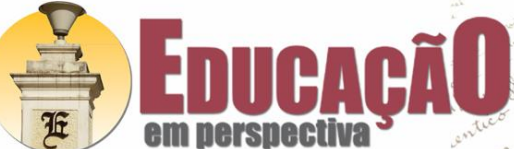

244/2009, que institui o Programa Emergencial de Formação de Professores em exercício na Educação Básica Pública e estabelece outras providências. Londrina, PR: 2011. Disponível em: http://www.uel.br/prograd/docs_prograd/deliberacoes/deliberacao_01_11.pdf. Acesso em: 16 mar. 2018.

UEL. Universidade Estadual de Londrina. Resolução CEPE/CA n ${ }^{\circ}$ 0245/2009. Estabelece o Projeto Pedagógico do curso de Primeira Licenciatura em Pedagogia integrante do Programa Emergencial de Formação de Professores em exercício na Educação Básica Pública. Londrina, PR: 2009. Disponível em: http://www.uel.br/prograd/docs_prograd/resolucoes/ 2009/resolucao_0245_09.pdf. Acesso em: 16 mar. 2018.

UEL. Universidade Estadual de Londrina. Resolução CEPE $n^{0} 0051$, de 08 de junho de 2010. Regulamenta a criação de cursos na modalidade a distância na UEL. Londrina, PR: 2010. Disponível em:http://www.uel.br/prograd/docs_prograd/resolucoes/2010/resolucao 51_10.pdf. Acesso em: 16 mar. 2018.

UEM. Universidade Estadual de Maringá. Núcleo de Educação a Distância (NEAD). s.d. Disponível em: http://portal.nead.uem.br/. Acesso em: 6 jan. 2018.

UEPG. Universidade Estadual de Ponta Grossa. Núcleo de Tecnologia e Educação Aberta e a Distância. 2009. Disponível em: https://ead.uepg.br/apl/Curso_polo/index.php? page=ListaCursos\#. Acesso em: 5 jan. 2018.

UFPR. Universidade Federal do Paraná. s.d. Disponível em: http://www.ufpr.br/ portalufpr/. Acesso em: 5 jan. 2018.

UFRGS. Universidade Federal do Rio Grande do Sul. Secretaria de Educação a Distância (SEAD UFRGS). s.d. Disponível em: http://www.ufrgs.br/sead. Acesso em: 6 jan. 2018.

UFSC. Universidade Federal de Santa Catarina. s.d. Disponível em: https://ead.ufsc.br/. Acesso em: 6 jan. 2018.

UFSM. Universidade Federal de Santa Maria. Núcleo de Tecnologia Educacional. s.d. Disponível em: https://nte.ufsm.br/. Acesso em: 2 jan. 2018.

UNICENTRO. Universidade Estadual do Centro Oeste. Núcleo de Ensino a Distância (NEAD). 2015. Disponível em: https://ead.unicentro.br/. Acesso em: 5 jan. 2018. 


\section{Sobre as Autoras}

${ }^{1}$ Sandra Letícia Schroeder Iglesias - Professora Pedagoga da SEED e docente colaboradora na Universidade Estadual do Centro Oeste. E-mail: sandraletigle@ hotmail.com - ORCID:

https://orcid.org/0000-0001-7779-7298

${ }^{2}$ Maria Luísa Furlan Costa - Doutora em Educação pela Universidade Paulista Júlio de Mesquita Filho. Professora adjunta da Universidade Estadual de Maringá. E-mail: luisafurlancosta@gmail.com - ORCID: http://orcid.org/0000-0002-7838-0459 